\title{
The effect of two pre-cryopreservation single layer colloidal centrifugation protocols in combination with different freezing extenders on the fragmentation dynamics of thawed equine sperm DNA
}

\author{
Luna Gutiérrez-Cepeda ${ }^{1 *}$, Álvaro Fernández ${ }^{1}$, Francisco Crespo ${ }^{2}$, Miguel Ángel Ramírez ${ }^{3}$, Jaime Gosálvez ${ }^{4}$ \\ and Consuelo Serres ${ }^{1}$
}

\begin{abstract}
Background: Variability among stallions in terms of semen cryopreservation quality renders it difficult to arrive at a standardized cryopreservation method. Different extenders and processing techniques (such us colloidal centrifugation) are used in order to optimize post-thaw sperm quality. Sperm chromatin integrity analysis is an effective tool for assessing such quality. The aim of the present study was to compare the effect of two single layer colloidal centrifugation protocols (prior to cryopreservation) in combination with three commercial freezing extenders on the post-thaw chromatin integrity of equine sperm samples at different post-thaw incubation $\left(37^{\circ} \mathrm{C}\right)$ times (i.e., their DNA fragmentation dynamics).

Results: Post-thaw DNA fragmentation levels in semen samples subjected to either of the colloidal centrifugation protocols were significantly lower $(p<0.05)$ immediately after thawing and after $4 \mathrm{~h}$ of incubation at $37^{\circ} \mathrm{C}$ compared to samples that underwent standard (control) centrifugation. The use of InraFreeze ${ }^{\circledR}$ extender was associated with significantly less DNA fragmentation than the use of Botu-Crio ${ }^{\circledR}$ extender at $6 \mathrm{~h}$ of incubation, and than the use of either Botu-Crio ${ }^{\circledR}$ or Gent $^{\circledR}$ extender at $24 \mathrm{~h}$ of incubation $(p<0.05)$.

Conclusions: These results suggest that single layer colloidal centrifugation performed with extended or raw semen prior to cryopreservation reduces DNA fragmentation during the first four hours after thawing. Further studies are needed to determine the influence of freezing extenders on equine sperm DNA fragmentation dynamics.
\end{abstract}

Keywords: Colloidal centrifugation, Equine sperm, DNA fragmentation, Cryopreservation, Equipure ${ }^{\circledR}$

\section{Background}

The use of cryopreserved equine sperm is becoming increasingly important in breeding strategies. However, variability among stallions in terms of semen cryopreservation quality renders it difficult to arrive at a standardized cryopreservation method $[1,2]$. Neither are there standard methods for determining pre-cryopreservation

\footnotetext{
* Correspondence: luna.gutierrez@vet.ucm.es

${ }^{1}$ Animal Medicine and Surgery Deparment, Veterinary Faculty, UCM, Avda. Puerta de Hierro s/n, Ciudad Universitaria, 28040 Madrid, Spain Full list of author information is available at the end of the article
}

nor post-thaw sperm quality, nor indeed are there any standard artificial insemination protocols [3].

Traditional laboratory methods are unable to accurately determine the fertility of cryopreserved semen [4]. Spermatozoa with damaged chromatin appear normal in terms of their membrane integrity, morphology and motility, but their use would lead to post-fertilization embryo failure [5]. The need to include sperm chromatin integrity analysis in the assessment of semen has been indicated by several authors who report a direct correlation between fertility and sperm chromatin integrity

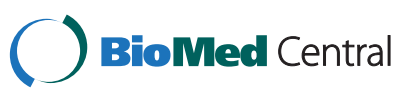


[6] but a poor correlation between fertility and the classically measured sperm quality variables [7-10]. The analysis of DNA fragmentation dynamics is important since DNA can become fragmented during this time, even within the female reproductive tract.

Certainly, López-Fernández et al. [9] and CortésGutiérrez et al. [11] have shown, at least in vitro, that the DNA of thawed semen incubated at $37^{\circ} \mathrm{C}$ becomes less stable over time. Moreover, it is important the use of the dynamic form of the Sperm DNA Fragmentation (SDF) assay for evaluating centrifugation and / or other ex vivo procedures, as a single basal assessment of SDF may inadvertently result in a false-positive evaluation of DNA quality [6].

The wide variability among stallions in terms of how well their semen can be cryopreserved demands that test freezing be performed to determine which technique is most suitable in each case [12]. This is particularly important when dealing with "bad freezer stallions", a significant problem among Purebred Spanish horses.

The pre-cryopreservation colloidal centrifugation of equine semen can increase the post-thaw number of sperm cells with normal morphology, as well as improve sperm motility (and sperm motility characteristics), membrane integrity and viability [6,13-18]. Certainly, colloidal centrifugation selects spermatozoa with intact and mature chromatin, which have a higher density than immature or damaged sperm [19-21]; further, the removal of damaged or dead spermatozoa and leukocytes may help maintain sperm chromatin integrity by preventing future damage caused by reactive oxygen species (ROS) $[10,19,20]$. The advantages of such centrifugation become more evident when semen is preserved cooled or in a state of cryopreservation [20]. Colloidal centrifugation can also eliminate pathogens from semen [22-26].

Although the use of colloidal centrifugation has been correlated with lower sperm DNA fragmentation levels in fresh, cooled [10,19,20,25,27] and cryopreserved semen (with centrifugation performed before or after the cryopreservation step) $[17,28,29]$, few studies have examined the dynamics of DNA fragmentation. To our knowledge this is the first study that combines the effect of colloidal centrifugation prior to cryopreservation and equine freezing extenders on the dynamics of DNA fragmentation over the post-thaw time.

The aim of the present study was to compare the effect of two single layer colloidal centrifugation protocols (prior to cryopreservation), developed at our laboratory [21] in combination with three commercial freezing extenders on the post-thaw chromatin integrity of equine sperm samples at different post-thaw incubation $\left(37^{\circ} \mathrm{C}\right)$ times (i.e., the fragmentation dynamics of the sperm DNA).

\section{Methods}

Animals

Seventeen ejaculates (2-3 per stallion) were obtained between January and March 2010 from six Purebred Spanish horses at the Depósito de Sementales de Ávila (FESCCR) $\left(40.66^{\circ} \mathrm{N} 4.70^{\circ} \mathrm{W}\right)$, Spain. The donor stallions, all between 7 and 15 years of age, were clinically healthy and of documented fertility. The diets and housing of these horses were those deemed to keep them in optimum condition.

\section{Semen collection and pre-cryopreservation analysis}

Semen was collected by allowing the stallions to mount a phantom, using a Missouri-model artificial vagina (Nasco, Fort Atkinson, WI, USA) warmed to $45-50^{\circ} \mathrm{C}$ and lubricated with a sterile non-spermicidal gel (IMV Technologies, L'Aigle, France). A mare in oestrous was used to induce sexual activity. After stabilization of the extragonadal sperm reserves (daily collection) semen was collected on a regular basis (two collections/week).

The gel-free ejaculates (maintained at $37^{\circ} \mathrm{C}$ ) were evaluated for volume using a graduated test tube, sperm motility and concentration using a computerized analysis system running ISAS ${ }^{\circledR}$ software [PROYSER, Madrid, Spain].

\section{Semen centrifugation}

Samples of all ejaculates were subjected to each of the following treatments (Figure 1).

- Standard control centrifugation (SCC): $10 \mathrm{ml}$ of semen extended 1:1 v:v with Inra96 ${ }^{\circledR}$ (IMV technologies, L'Aigle, France) were placed in a $50 \mathrm{ml}$ Falcon tube and centrifuged at $450 \mathrm{~g}$ for $7 \mathrm{~min}$.

- Colloidal centrifugation Protocol 1: $10 \mathrm{ml}$ of semen extended 1:1 v:v with Inra96 ${ }^{\circledR}$ were placed on top of a $10 \mathrm{ml}$ layer of Bottom Layer ${ }^{\circledR}$ EquiPure $^{\circledR}$

[Nidacon, International AB, Mölndal, Sweden] equilibrated at $22^{\circ} \mathrm{C}$ in a $50 \mathrm{ml}$ Falcon tube. Care was taken to avoid mixing the sperm and colloid phases. The loaded tubes were centrifuged at $300 \mathrm{~g}$ for $20 \mathrm{~min}$.

- Colloidal centrifugation Protocol 2: $5 \mathrm{ml}$ of raw semen (i.e., without extender) were placed over $5 \mathrm{ml}$ of Bottom Layer ${ }^{\circledR}$ EquiPure ${ }^{\circledR}$ following the same instructions as in Protocol 1.

- After centrifugation, the supernatant (semen extender, seminal plasma and colloid) was removed by aspiration. The resulting sperm pellets were resuspended for cryopreservation in the presence of different extenders.

\section{Cryopreservation with different extenders}

The required volume of each pellet was taken to obtain a final sperm concentration of $50 \times 10^{6} \mathrm{ml}^{-1}$ in $5 \mathrm{ml}$ 


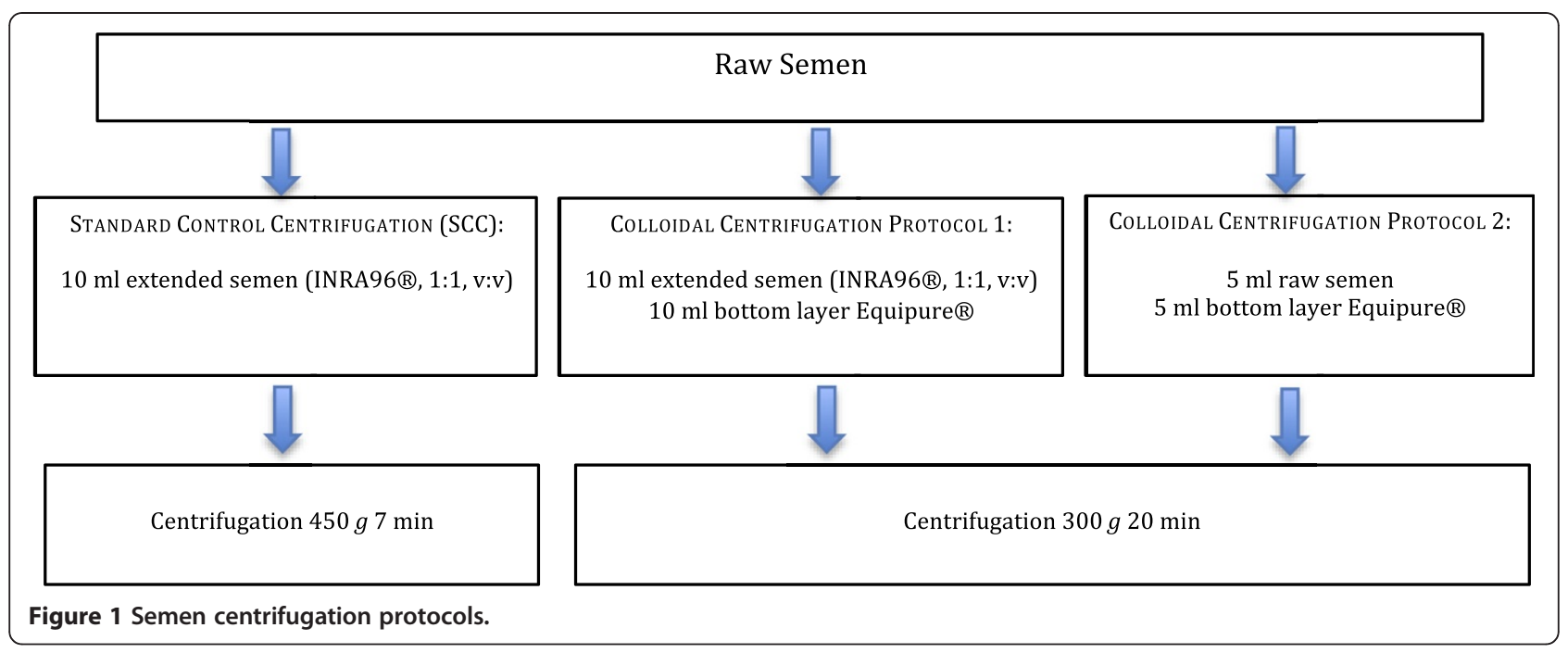

of each of three commercial freezing extenders: Gent ${ }^{\circledR}$ (Minitüb ${ }^{\circledR}$, Abfullund Labortechnik GmbH \& Co., Tiefenbach, Germany), InraFreeze ${ }^{\circledR}$ (IMV technologies, L'Aigle, France) and Botu-Crio ${ }^{\circledR}$ (BioTech, Botucatu, Sao Paulo, Brazil) (total number of treatments therefore $=9$; see Figure 2). After resuspension, the semen was packed into $0.5 \mathrm{ml}$ polyvinyl chloride straws (IMV International, St Paul, MN, USA). The straws containing sperm extended with Gent $^{\circledR}(G)$ extender were frozen without prior cooling $[30,31]$. Those containing sperm extended with InraFreeze ${ }^{\circledR}$ (I) were frozen after being slowly cooled to $4^{\circ} \mathrm{C}$ at a rate of $0.3^{\circ} \mathrm{C} / \mathrm{min}$, as recommended by the manufacturer. Finally, those containing sperm extended with Botu-Crio ${ }^{\circledR}$ (B) were frozen after being cooled at $4-6^{\circ} \mathrm{C}$ for $20 \mathrm{~min}$, as recommended by the manufacturer. In all cases the straws were frozen horizontally in racks placed $4 \mathrm{~cm}$ above the surface of liquid nitrogen for $7 \mathrm{~min}$, after which they were plunged into this liquid nitrogen as described by Cochran et al. [30].

\section{Assessment of post-thaw sperm chromatin integrity}

After 4 weeks of storage the straws were thawed by immersion in a water bath at $37^{\circ} \mathrm{C}$ for $1 \mathrm{~min}$. Sperm chromatin integrity was assessed via the sperm chromatin dispersion test [9] making use of the Equus-Halomax ${ }^{\circledR}$ Kit (Halotech DNA, SL., Madrid, Spain). The degree of

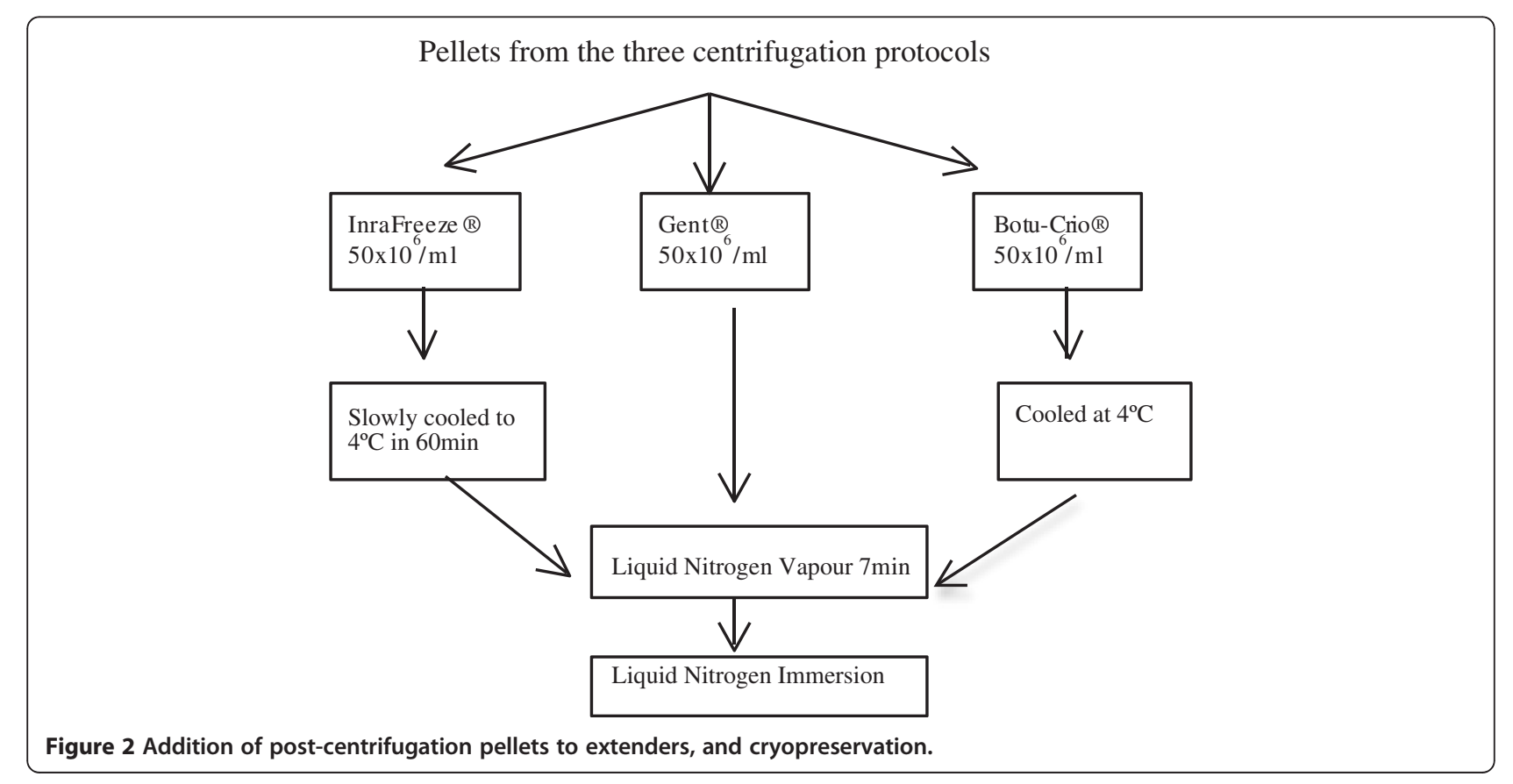


Table $1 \mathrm{sDFl}$ value groups (means \pm SD)

\begin{tabular}{|c|c|c|}
\hline \multirow[t]{2}{*}{ STALLION } & \multicolumn{2}{|c|}{ Sperm DNA fragmentation index (sDFI) } \\
\hline & Low average levels & High average levels \\
\hline B & $15.8135^{b} \pm 8,88$ & \\
\hline C & $18.3176^{\mathrm{b}} \pm 9,34$ & \\
\hline $\mathrm{F}$ & $19.4167^{b} \pm 13,95$ & \\
\hline A & $20.2345^{b} \pm 12,73$ & \\
\hline D & & $27.1280^{\mathrm{a}} \pm 13,20$ \\
\hline$E$ & & $30.9288^{\mathrm{a}} \pm 14,97$ \\
\hline
\end{tabular}

DNA damage in each sample was quantified using the sperm DNA fragmentation index (sDFI), which reflects the percentage of cells with fragmented DNA.

An aliquot of sperm from each straw was diluted to $10 \times 10^{6} \mathrm{ml}^{-1}$ and processed following the kit instructions. DNA damage was visualized using a Proyser fluorescent microscope (Proyser, Madrid, Spain) employing SyberGreen II fluorochrome at 40x concentration. Sperm heads showing a large halo of chromatin dispersion were understood to contain highly fragmented DNA. The percentage of spermatozoa with such fragmented DNA was calculated and expressed as a percentage of the total sperm count. Observations were made at 0, 4, 6 and $24 \mathrm{~h}$ of incubation in a $37^{\circ} \mathrm{C}$ water bath.

\section{Statistical analysis}

ANOVA and DUNCAN test were used to compare sDFI values. Repeat measures analysis (with Greenhouse correction) was performed to follow the change in sDFI over incubation time (within-subjects factor), considering the variable 'donor' as a source of variation (between-subjects factor). The influence of the interaction incubation time $\times$ donor on sDFI was also examined.
Significance was set at $\mathrm{p}<0.05$. Data were processed using the IBM ${ }^{\circledR}$ SPSS $-19^{\circledR}$ statistical package.

\section{Results}

Media sperm concentration value in fresh semen was $273,35 \times 10^{6}$ spermatozoa/ml (range between 189,9 and $361 \times 10^{6}$ spermazoa/ml). After centrifugation, the average sperm concentration of the colloidal-centrifuged pellets (Protocols 1 and 2) was approximately half that of the SCC pellets $(544.5$ million sperm $/ \mathrm{ml}$ and a $57.79 \%$ sperm yield vs. 928 million sperm $/ \mathrm{ml}$ and a $98.5 \%$ sperm yield).

Significant differences were seen between stallion donors in terms of mean sDFI $(p<0.05)$. Two groups with significantly different mean sDFI values were established: low $(<20.23 \%)$ and high $(>27.13 \%)$ (Table 1$)$.

The sDFI values increased over incubation time for each ejaculate in all nine treatments (Table 2). However, this increase was different in different donors, with the interaction incubation time $x$ donor having a significant effect on the sDFI value $(\mathrm{p}<0.05)$ (Figure 3$)$.

A comparison of the sDFI values at different incubation times between the nine treatments (Table 2) showed no significant difference between them at 0 and $6 \mathrm{~h}$. However, at $4 \mathrm{~h}$ of incubation Protocol 2 was associated with a trend towards lower sDFI values (less DNA fragmentation); indeed significant differences $(\mathrm{p}<0.05)$ were detected between the I-2 treatment and the $\mathrm{B}-\mathrm{C}$ treatment (sDFI 14.22 and 22.16 respectively), and between the G-2 treatment and the B-C treatment (sDFI 14.44 and 22.16 respectively).

At $24 \mathrm{~h}$ of incubation, the InraFreeze ${ }^{\circledR}$ extender tended to improve the sDFI results for all centrifugation protocols, with significant differences $(\mathrm{p}<0.05)$ seen between the I-2 and B-C treatments (sDFI 25.94 compared to 39.40), between the I-2 and G-C treatments (sDFI 25.94 compared to 41.83), and between the I-1 and G-C treatments (sDFI 30.55 compared to 41.83).

Table 2 Average DNA fragmentation values associated with the centrifugation+extender treatments (means \pm SD)

\begin{tabular}{|c|c|c|c|c|}
\hline Treatment & sDFI 0 & sDFI 4 & sDFI 6 & sDFI 24 \\
\hline$B-C$ & $16.36^{a} \pm 11,56$ & $22.15^{b} \pm 11,58$ & $27.01^{a} \pm 15,66$ & $38.40^{\text {b. }} c_{ \pm 13,23}$ \\
\hline B-1 & $13.23^{\mathrm{a}} \pm 7,08$ & $16.06^{\mathrm{a} \cdot \mathrm{b}} \pm 5,64$ & $27.07^{\mathrm{a}} \pm 7,37$ & $35.95^{\text {a. b. }} c_{ \pm} \pm 10,38$ \\
\hline B-2 & $11.86^{\mathrm{a}} \pm 5,87$ & $18.11^{\text {a. }}{ }_{ \pm 7,32}$ & $23.13^{\mathrm{a}} \pm 8,62$ & $33.91^{\text {a. b. }} c_{ \pm 14,50}$ \\
\hline I-C & $14.61^{\mathrm{a}} \pm 5,84$ & $18.43^{\text {a. }} \pm \pm 7,17$ & $23.51^{\mathrm{a}} \pm 14,28$ & $31.13^{\text {a. b. }} c_{ \pm} \pm 15,59$ \\
\hline $1-1$ & $14.52^{\mathrm{a}} \pm 10,70$ & $19.55^{\mathrm{a} \cdot \mathrm{b}} \pm 15,61$ & $20.81^{\mathrm{a}} \pm 9,15$ & $30.54^{a \cdot b}{ }^{2}+16,94$ \\
\hline $1-2$ & $13.69^{\mathrm{a}} \pm 10,39$ & $14.22^{\mathrm{a}} \pm 8,73$ & $17.81^{\mathrm{a}} \pm 8,45$ & $25.94^{\mathrm{a}} \pm 10,24$ \\
\hline $\mathrm{G}-\mathrm{C}$ & $17.01^{\mathrm{a}} \pm 10,64$ & $17.17^{\mathrm{a} \cdot \mathrm{b}} \pm 7,19$ & $23.69^{\mathrm{a}} \pm 12,14$ & $41.83^{c} \pm 19,39$ \\
\hline G-1 & $12.75^{\mathrm{a}} \pm 8.86$ & $17.87^{\mathrm{a} \cdot} \mathrm{b}_{ \pm 9,06}$ & $24.44^{a} \pm 11,16$ & $34.99^{\text {a. b. }} c_{ \pm} \pm 8,76$ \\
\hline $\mathrm{G}-2$ & $11.96^{\mathrm{a}} \pm 6,23$ & $14.44^{\mathrm{a}} \pm 8,82$ & $22.44^{\mathrm{a}} \pm 17,71$ & $34.74^{\text {a. b. }} c_{ \pm} 15,32$ \\
\hline
\end{tabular}

DNA fragmentation index values immediately after thawing (sDFI 0) and after 4 (sDFI 4), 6 (sDFI 6) and $24 \mathrm{~h}$ (sDFI 24) of incubation. Treatments: C,standard control centrifugation, 1, colloidal centrifugation Protocol 1, 2, colloidal centrifugation Protocol 2, B, Botu-Crio ${ }^{\circledR}, I$, InraFreeze ${ }^{\circledR}, G$, Gent ${ }^{\circledR}$. Letters in superscript represent significant differences between extenders $(p<0.05)$ at each time point. 


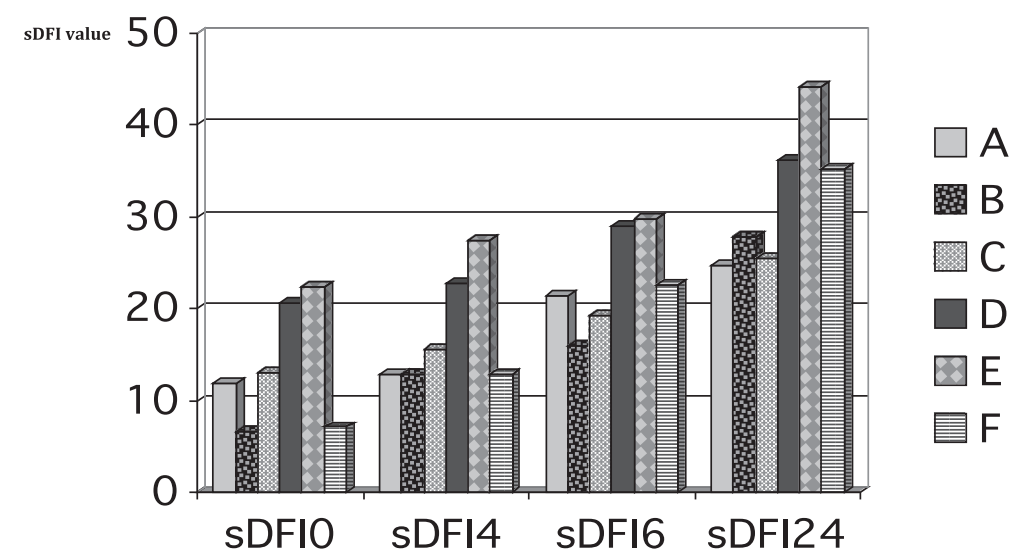

Figure 3 DNA fragmentation values (sDFI) over incubation time for the different stallions. Legend: Average DNA fragmentation index values immediately post-thawing (sDFI 0) and after 4 (sDFI 4), 6 (sDFI 6) and 24 (sDFI 24) hours of incubation. Letters (A-F) represent the different stallions. sDFI values increased significantly with time $(p<0.05)$, but not equally so across all the stallions $(p<0.05)$.

Irrespective of the centrifugation protocol followed, the sDFI values obtained at $6 \mathrm{~h}$ of incubation at $37^{\circ} \mathrm{C}$ were significantly $(\mathrm{p}<0.05)$ lower with InraFreeze ${ }^{\circledR}$ extender than with Botu-Crio ${ }^{\circledR}$ extender (Table 3). At $24 \mathrm{~h}$, the sDFI values obtained with the InraFreeze ${ }^{\circledR}$ extender were lower than those obtained with either Botu-Crio ${ }^{\circledR}$ or Gent ${ }^{\circledR}$ extender.

Table 4 shows the sDFI values at different incubation times obtained with the different centrifugation protocols irrespective of the extender used. Both Protocol 1 and 2 returned significantly $(\mathrm{p}<0.05)$ lower sDFI values at $0 \mathrm{~h}$ than the SCC protocol. At $4 \mathrm{~h}$, only Protocol 2 returned significantly lower SDFI values than the SCC protocol. No significant differences were found between any of the three centrifugation protocols at 6 or $24 \mathrm{~h}$ of incubation, although the values returned by Protocol 2 tended to be lower.

\section{Discussion}

The present sDFI results show variability between the donor stallions in terms of their post-thaw sperm DNA integrity. This is not surprising given the individual variability commonly seen in stallion sperm [2,3,32]. Horses have undergone selection primarily with pedigree in mind or for their ability to provide a particular type of service. In some cases, however, this has led to reduce fertility $[9,15,20,23,33]$. In the present work, the range of post-thaw sDFI values immediately after thawing
(6.55-22.46\%) recorded is similar to that reported by López-Fernández et al. [9] (4.2-26.3\%).

Individual variability was observed in the DNA fragmentation dynamics recorded, as reported earlier by LópezFernández et al. [9]. In the present study, the sDFI values (i.e., DNA fragmentation levels) increased significantly with incubation time, as reported by other authors $[6,9,34]$. The largest increase occurred between $6 \mathrm{~h}$ and 24 $\mathrm{h}$ of incubation, not between $1 \mathrm{~h}$ and $6 \mathrm{~h}$ as described by López-Fernández et al. [9]. This may be significant since there is increasing evidence that the integrity of the sperm chromatin at the actual time of fertilization influences embryo survival [9]; poor sperm DNA integrity may account for some of the infertility commonly thought to lie with mares.

Hoogewijs et al. [28] obtained an average sDFI immediately after thawing of around $12 \%$ in colloidally-selected stallion sperm samples cryopreserved with Botu-Crio ${ }^{\circledR}$, while Cortés-Gutiérrez et al. [35] reported values of $18-22 \%$ in non-colloidally-selected donkey sperm samples frozen with Gent ${ }^{\circledR}$. The present results are consistent with the findings of these authors $(13.24 \%$ for B-1, $11.86 \%$ for B-2 and 17.1\% for G-C), although different DNA integrity evaluation techniques were used (SCSA, N-Comet Assay and the sperm chromatin dispersion test respectively).

No differences were seen in the sDFI between any of the nine treatments immediately after thawing. However, the use of InraFreeze ${ }^{\circledR}$ was associated with a trend towards

Table 3 Average DNA fragmentation associated with the use of the different freezing extenders (means \pm SD)

\begin{tabular}{lllll}
\hline Extender & sDFI 0 & sDFI 4 & sDFI 6 & sDFI 24 \\
\hline Botu-Crio $^{\circledR}$ & $13,82^{\mathrm{a}} \pm 8,57$ & $18,78^{\mathrm{a}} \pm 8,76$ & $25,74^{\mathrm{b}} \pm 11,10$ & $36,08^{\mathrm{b}} \pm 12,70$ \\
InraFreeze $^{\circledR}$ & $14,27^{\mathrm{a}} \pm 9,07$ & $17,40^{\mathrm{a}} \pm 11,15$ & $20,77^{\mathrm{a}} \pm 12,74$ & $29,18^{\mathrm{a}} \pm 14,39$ \\
Gent $^{\circledR}$ & $13,91^{\mathrm{a}} \pm 8,88$ & $16,49^{\mathrm{a}} \pm 8,36$ & $23,52^{\mathrm{a},}{ }^{\mathrm{b}} \pm 13,71$ & $37,19^{\mathrm{b}} \pm 15,20$ \\
\hline
\end{tabular}

DNA fragmentation index average values immediately after thawing (sDFI 0) and after 4 (sDFI 4), 6 (sDFI 6) and $24 \mathrm{~h}$ (sDFI 24$)$ of incubation. Letters in superscript represent significant differences between extenders $(p<0.05)$ at each time point. 
Table 4 Average DNA fragmentation values associated with the different centrifugation protocols (means \pm SD)

\begin{tabular}{lllll}
\hline Centrifugation Protocol & sDFI 0 & sDFI 4 & sDFI 6 & sDFI 24 \\
\hline Standard control centrifugation & $21.50^{\mathrm{b}} \pm 9,54$ & $24.31^{\mathrm{b}} \pm 8,97$ & $24.74^{\mathrm{a}} \pm 13,91$ & $37.12^{\mathrm{a}} \pm 16,56$ \\
Protocol 1 & $13.50^{\mathrm{a}} \pm 8,85$ & $17.83^{\mathrm{a} \cdot \mathrm{b}} \pm 10,79$ & $24.17^{\mathrm{a}} \pm 11,41$ & $33.90^{\mathrm{a}} \pm 12,40$ \\
Protocol 2 & $12.50^{\mathrm{a}} \pm 7,66$ & $15.59^{\mathrm{a}} \pm 8,35$ & $21.19^{\mathrm{a}} \pm 12,41$ & $31.53^{\mathrm{a}} \pm 13,86$ \\
\hline
\end{tabular}

DNA fragmentation index average values immediately after thawing (sDFI 0) and after 4 (sDFI 4), 6 (sDFI 6) and $24 \mathrm{~h}$ (sDFI 24) of incubation. Letters in superscript represent significant differences between extenders $(p<0.05)$ at each time point.

the improvement of the sDFI values, especially at $24 \mathrm{~h}$ of incubation; indeed significant differences $(\mathrm{p}<0.05)$ were seen between I-2 and B-C, I-2 and G-C, and I-1 and G-C.

Irrespective of the centrifugation protocol followed, InraFreeze ${ }^{\circledR}$ significantly reduced the sDFI values at $6 \mathrm{~h}$ compared to Botu-Crio ${ }^{\circledR}$, and at $24 \mathrm{~h}$ of incubation compared to both Botu-Crio ${ }^{\circledR}$ and Gent ${ }^{\circledR}$. Some authors report that egg yolk-based extenders better protect chromatin structure than skimmed milk-based extenders, at least in bovine sperm [36]. Carvalho et al. [37], in contrast, report the extender employed to have no influence on DNA integrity. However, it should be noted that, in these two studies, the SDFI was analysed immediately after thawing; no post-thaw incubation study was undertaken - and DNA integrity would be most strongly affected during such an incubation period. The precise mechanism by which egg yolk aids in the protection of spermatozoa during the freeze-thaw process is unknown [38], but low density lipoproteins present in egg yolk plasma are widely presumed to be the cryoprotective agent $[38,39]$. Further, there is increasing evidence that cryoprotective antagonists may exist in other egg yolk fractions $[38,39]$. The above may explain the better sDFI values obtained with InraFreeze ${ }^{\circledR}$, which contains only egg yolk plasma rather than whole egg yolk as in Botu$\mathrm{Crio}^{\circledR}$ and Gent ${ }^{\circledR}$. Replacing egg yolk with sterilized egg yolk plasma might remove a potential source of cryoprotective antagonists [39].

In the present work, single layer colloidal centrifugation prior to cryopreservation (Protocols 1 and 2) led to significantly lower $(\mathrm{p}<0.05)$ sDFI values than the SCC protocol immediately after thawing. These data are consistent with those obtained by other authors for human sperm [40,41], fresh equine semen [19-21,25], cooled equine semen [10] and cryopreserved equine semen subjected to colloidal centrifugation before freezing $[28,29]$ or after thawing $[17,29]$. However, these authors performed no DNA fragmentation dynamics analysis.

The present results showed the I-2 and G-2 treatments to return significantly lower sDFI values than the B-C treatment at $4 \mathrm{~h}$ of incubation. At $24 \mathrm{~h}$ of incubation, Protocol 2 was associated with the best sDFI values for all three extenders. Crespo et al. [6] found no differences in SDFI values at time 0 of incubation between colloidal, standard or non- centrifuged equine fresh sperm samples, but as we found, after incubation at $37^{\circ} \mathrm{C}$ samples subjected to colloidal centrifugation exposed lower sDFI values than non-selected sperm both for fresh and cooled equine semen, what can be related to higher longevity in the selected sperm. Macías García et al. [42] have recently proved that colloidal centrifugation selects a spermatozoa subpopulation that clearly responds differently to osmotic shock, which could better withstand cooling procedures.

Sperm yield obtained from SCC was superior to what is usually described in the literature for simple centrifugation (400-600 g), where average losses are 20-25\% $[20,31]$ However, average sperm yields were similar to those obtained by Hoogewijs et al. [28] for colloidal centrifugation ( $57.79 \%$ vs. $50.9 \%)$ protocols. Hoogewijs et al. [28] reported colloidal centrifugation prior to cryopreservation to be associated with lower sperm yields than standard centrifugation. However, we agree with the theory of these authors that indicate that these lower sperm yields might be offset if colloidally-selected sperm better withstood cryopreservation, thus reducing the sperm dose required to guarantee conception.

In the present work most sperm DNA damage occurs during incubation, not in the first minutes after thawing, in concordance with other authors $[6,9]$. This fact remarks the importance of the use of the dynamic form of the SDF assay for evaluating ex vivo procedures [6]. sDFI values were significantly lower immediately after thawing and remained so in the colloidally-selected samples during the first four hours of incubation (24.31 for the SCC protocol vs. 15.59 for Protocol 2). Although there were no significant differences in SDFI values between the SCC protocol and Protocol 1, in the SCC protocol DNA damage occurred more quickly and was more intense. Crespo et al. [6], López-Fernández et al. [9] and Cortés-Gutiérrez et al. [11] indicate that slower DNA fragmentation dynamics may be associated with greater sperm viability in the female genital tract. The results suggest that colloidal centrifugation before cryopreservation would be beneficial in terms of spermatic survival after insemination with frozen-thawed sperm, although further studies are necessary to confirm a possible relation between our "in vitro" observations and "in vivo" fertility.

\section{Conclusion}

Single layer colloidal centrifugation performed with extended or raw semen prior to cryopreservation reduces 
DNA fragmentation during the first four hours after thawing (while incubating at $37^{\circ} \mathrm{C}$ ). Further studies are needed to determine the influence of freezing extenders on equine sperm DNA fragmentation dynamics.

\section{Abbreviations}

ROS: Reactive Oxygen Species; SCC: C, Standard Control Centrifugation; 1: Colloidal centrifugation Protocol 1; 2: Colloidal centrifugation Protocol 2; sDFI: Sperm DNA Fragmentation Index; B: Botu-Crio ${ }^{\circledR}$; I: Inrafreeze ${ }^{\circledR}$; G: Gent ${ }^{\circledR}$.

\section{Competing interests}

The authors declare that they have no competing interests.

\section{Authors' contributions}

The study was conceived by CS conceived the study and together with FC and JG participated in its design and coordination. LG-C, AF and FC performed the semen collection, processing of samples for centrifugation and cryopreservation, and helped by MAR, JG and CS performed the SDFI dynamic assay. LG and CS did the statistical analysis and with FC interpreted the data. The manuscript was written by LG-C helped by CS. AF, MAR, FC and JG revised it critically. All authors have read and approved the final version of the manuscript.

\section{Acknowledgements}

The authors are indebted to the FESCCR for their assistance in this work, to Pedro Cuesta for statistical assistance, and Adrian Burton for editorial and language assistance. This study was funded by Equipos VeterinariosBiológicos, S.L. Gutiérrez-Cepeda, L. was supported by MICINN FPU fellowship AP2008-02034.

\section{Author details}

${ }^{1}$ Animal Medicine and Surgery Deparment, Veterinary Faculty, UCM, Avda. Puerta de Hierro s/n, Ciudad Universitaria, 28040 Madrid, Spain. ${ }^{2}$ Centro Militar de Cría Caballar, (FESCCR-Ministerio de Defensa), Ávila, Spain. ${ }^{3}$ Halotech DNA, S.L. UAM, Madrid, Spain. ${ }^{4}$ Biology Department, Genetic Unity, UAM, Madrid, Spain.

Received: 10 September 2012 Accepted: 9 October 2012 Published: 5 December 2012

\section{References}

1. Metcalf ES: The efficient use of equine cryopreserved semen. Theriogenology 2007, 68:423-428.

2. Sieme $H$, Harrison RAP, Petrunkina AM: Cryobiological determinants of frozen semen quality, with special reference to stallion. Anim Reprod Sci 2008, 107:276-292.

3. Samper JC, Morris CA: Current methods for stallion semen cryopreservation: a survey. Theriogenology 1998, 49:895-903.

4. Kuisma P, Andersson M, Koskinen E, Katila T: Fertility of frozen-thawed stallion semen cannot be predicted by the currently used laboratory methods. Acta Vet Scand 2006, 48:14

5. Fatehi AN, Bevers MM, Schoevers E, Roelen BAJ, Colenbrander B, Gadella BM: DNA damage in bovine sperm does not block fertilization and early embryonic development but induces apoptosis after the first cleavages. J Androl 2006, 27:176-188.

6. Crespo F, Gosalvez J, Gutiérrez-Cepeda L, Serres C, Johnston SD: Colloidal centrifugation of stallion semen results in a reduced rate of sperm DNA fragmentation. Reprod Dom Anim 2012, doi:10.1111/j.1439-0531.2012.02140. x ISSN 0936-6768.

7. Love CC, Kenney RM: The relationship of increased susceptibility of sperm DNA to denaturation and fertility in the stallion. Theriogenology 1998, 50:955-972.

8. Madrid-Bury N, Pérez-Gutiérrez JF, Pérez-Garnelo S, Moreira P, Sanjuanbenito BP, Gutiérrez-Adán A, de la Fuente Martínez J: Relationship between nonreturn rate and chromatin condensation of deep frozen bull spermatozoa. Theriogenology 2005, 64:232-241.

9. López-Fernández C, Crespo F, Arroyo F, Fernández JL, Arana P, Johnston SD, Gosálvez J: Dynamics of sperm DNA fragmentation in domestic animals II. The stallion. Theriogenology 2007, 68:1240-1250.
10. Morrell JM, Johannisson H, Strutz H, Dalin A-M, Rodriguez-Martinez H: Colloidal centrifugation of stallion semen: changes in sperm motility, velocity, and chromatin integrity during storage. J Equine Vet Sci 2009, 29(Suppl 1):24-32.

11. Cortés-Gutiérrez El, Crespo F, Gosálvez A, Dávila-Rodríguez MI, LópezFernández C, Gosálvez J: DNA fragmentation in frozen sperm of Equus asinus: Zamorano_leonés, a breed at risk of extinction. Theriogenology 2008, 69:1022-1032.

12. Loomis PR, Graham JK: Commercial semen freezing: Individual male variation in cryosurvival and the response of stallion. Anim Reprod Sci 2008, 105:119-128.

13. Macpherson ML, Blanchard TL, Love CC, Brinsko SP, Varner DD: Use of a silane-coated silica particle solution to enhance the quality of ejaculated semen in stallion. Theriogenology 2002, 58:317-320.

14. Edmond AJ, Teague SR, Brinsko SP, Comerford KL, Waite JA, Mancill SS, Love CC, Varner DD: Effect of density-gradient centrifugation on quality and recovery rate of equine spermatozoa. Anim Reprod Sci 2008, 107(Suppl 3-4):318.

15. Morrell JM, Dalin A-M, Rodriguez-Martinez H: Prolongation of stallion sperm survival by centrifugation through coated silica colloids: a preliminary study. Anim Reprod Sci 2008, 5(Suppl 3-4):121-126.

16. Morrell JM, Pihla J, Dalin A-M, Johannisson A: Restoration of seminal plasma to stallion spermatozoa selected by colloid centrifugation increases sperm progressive motility but is detrimental to chromatin integrity. Theriogenology 2012, 78:345-352.

17. Macías García B, Morrell JM, Ortega-Ferrusola C, González-Fernández L, Tapia JA, Rodríguez-Martínez H, Peña FJ: Centrifugation on a single layer of colloid selects improved quality spermatozoa from frozen-thawed stallion semen. Anim Reprod Sci 2009, 114:193-202.

18. Macías García B, González Fernández L, Morrel JM, Ortega Ferrusola C, Tapia JA, Rodriguez Martínez H, Peña FJ: Single-layer centrifugation through colloid positively modifies the sperm subpopulation structure of frozen-thawed stallion spermatozoa. Reprod Dome Anim 2009, 44:523-526.

19. Johannisson A, Morrell JM, Thorén J, Jönsson M, Dalin A-M, RodriguezMartinez H: Colloidal centrifugation with Androcoll-ETM prolongs stallion sperm motility, viability and chromatin integrity. Anim Reprod Sci 2009, 116(Suppl 1-2):119-128.

20. Morrell JM, Johannisson A, Dalin A-M, Rodriguez-Martínez H: Morphology and chromatin integrity of stallion spermatozoa prepared by density gradient and single layer centrifugation through silica colloids. Reprod Dome Anim 2009, 44:512-517.

21. Gutiérrez-Cepeda L, Fernández A, Crespo F, Gósalvez J, Serres C: Simple and economic colloidal centrifugation protocols may be incorporated to the clinical equine sperm processing procedure. Anim Reprod Sci 2011, 124(Suppl 1-2):85-89.

22. Loomis PR: Advanced methods for handling and preparation of stallion semen. Vet Clin N Am: Equine 2006, 22(3):663-676.

23. Morrell JM, Dalin A-M, Rodriguez-Martínez $\mathrm{H}$ : Comparision of density gradient and single layer centrifugation of stallion spermatozoa: Yield, motility and survival. Equine Vet $J$ 2009, 41 (Suppl 1):53-58.

24. Morrell JM, Saravia F, Van Wienen M, Wallgren M, Rodriguez-Martínez H: Selection of boar spermatozoa using centrifugation on a glycidoxypropyltrimethoxylane-coated silica colloid. J Reprod Dev 2009, 55:547-552.

25. Morrell JM, Johannisson A, Dalin A-M, Rodriguez-Martínez H: Single-layer centrifugation with Androcoll-E can be scale up to allow large volumes of stallion ejaculate to be processed easily. Theriogenology 2009, 72:879-884.

26. Ortega-Ferrusola C, González-Fernández L, Muriel A, Macías-García B, Rodríguez-Martínez H, Tapia JA, Peña FJ: Does the Microbial Flora in the Ejaculate Affect the Freezeability of Stallion Sperm. Reprod Dom Anim 2009, 44:518-522.

27. Morrell JM, Rodriguez-Martinez $\mathrm{H}$, Johannisson A: Single layer centrifugation of stallion spermatozoa improves sperm quality compared with sperm washing. Reprod Biomed Online 2010, 21:429-436

28. Hoogewijs M, Morrell J, Van Soom A, Govaere J, Johannisson A, Piepers S, De Schauwer C, De Kruif A, De Vliegher S: Sperm selection using single layer centrifugation prior to cryopreservation can increase thawed sperm quality. Equine Vet J 2011, 43(Suppl 40):35-41. 
29. Mancill SS, Love CC, Brinsko SP, Edmond AJ, Foster ML, Teague JA: Effect of density gradient centrifugation on cryopreservation of equine spermatozoa. Anim Reprod Sci 2010, 121:208-209.

30. Cochran JD, Amann RP, Froman DP, Pickett BW: Effects of centrifugation, glicerol level, cooling to $5^{\circ} \mathrm{C}$, freezing rate and thawing rate on the postthaw motility of equine sperm. Theriogenology 1984, 22:25-38.

31. Pickett BW, Amann RP: Cryopreservation of semen. In Equine Reproduction. 2nd edition. Edited by McKinnon AO, Voss JL. Philaderphia: Lea \& Febiger; 1993:775-780

32. Aurich C: Recent advances in cooled-semen technology. Anim Reprod Sci 2008, 107:268-275.

33. Colenbrander B, Gadella BM, Stout TA: The predictive value of semen analysis in the evaluation of stallion fertility. Reprod Domest Anim 2003, 38:305-11.

34. Linfor JJ, Meyers SA: Detection of DNA damage in response to cooling injury in equine spermatozoa using single cell gel electrophoresis. $J$ Androl 2002, 23:107-113.

35. Cortés-Gutiérrez E, Crespo F, Serres-Dalmau C, Rozas AL Gdl, DávilaRodriguez MI, López-Fernández C, Gosálvez J: Assessment of Sperm DNA Fragmentation in Stallion (Equus caballus) and Donkey (Ewuus asinus) Using the Sperm Chromatin Dispersion Test. Reprod Dom Anim 2009, 44:823-828.

36. Karabinus DS, Evenson DP, Kaproth MT: Effects of egg yolk-citrate and milk extenders on chromatin structure and viability of cryopreserved bull sperm. J Dairy Sci 1999, 74:3836-3848.

37. Carvalho EC, Paes de Arruda R, Furugen A, Nascimento J, Fernandes J, Mazza PE: Effects that bovine sperm cryopreservation using two different extenders has on sperm membranes and chromatin. Anim Reprod Sci 2008, 104:119-131.

38. Moussa M, Martinet $\mathrm{V}$, Trimeche $\mathrm{A}$, Tainturier $\mathrm{D}$, Anton M: Low density lipoproteins extracted from hen egg yolk by an easy method: cryoprotective effect on frozen-thawed bull semen. Theriogenology 2002, 57(Suppl 6):1695-1706.

39. Pillet E, Duchamp G, Batellier F, Beaumal V, Anton M, Desherces S, Schmitt E, Magistrini M: Egg yolk plasma can replace egg yolk in stallion freezing extenders. Theriogenology 2011, 75(Suppl 1):105-114.

40. Sakkas D, Manicardi GC, Tomlinson M, Mandrioli M, Bizzaro D, Bianchi PG, Bianchi $U$ : The use of two density gradient centrifugation techniques and the swim-up method to separate spermatozoa with chromatin and nuclear DNA anomalies. Hum Reprod 2000, 15(Supple 5):1112-1116.

41. Tomlinson MJ, Moffatt O, Manicardi GC, Bizzaro D, Afnan M, Sakkas D: Interrelationships between seminal parameters and sperm nuclear DNA damage before and after density gradient centrifugation: implications for assisted conception. Hum Reprod 2001, 16(Supple 10):2160-2165.

42. Macías-García B, González-Fernández L, Gallardo-Bolañosa JM, Peña FJ, Johannisson A, Morrell JM: Androcoll-E large selects a subset of live stallion spermatozoa capable of producing ROS. Anim Reprod Sci 2012, 132:74-82.

doi:10.1186/1751-0147-54-72

Cite this article as: Gutiérrez-Cepeda et al:: The effect of two precryopreservation single layer colloidal centrifugation protocols in combination with different freezing extenders on the fragmentation dynamics of thawed equine sperm DNA. Acta Veterinaria Scandinavica $201254: 72$.

\section{Submit your next manuscript to BioMed Central and take full advantage of:}

- Convenient online submission

- Thorough peer review

- No space constraints or color figure charges

- Immediate publication on acceptance

- Inclusion in PubMed, CAS, Scopus and Google Scholar

- Research which is freely available for redistribution 